\title{
Using Digital Narratives to Support the Collaborative Learning and Exploration of Cultural Heritage
}

\author{
Paul Mulholland and Trevor Collins \\ Knowledge Media Institute, \\ The Open University, \\ Milton Keynes, MK7 6AA, UK \\ \{P.Mulholland $\mid$ T.D.Collins $\} @$ open.ac.uk
}

\begin{abstract}
Cultural institutions increasingly see the need to play an important role in the lifelong learning of citizens. Recent trends, particularly in science museums, have been toward supporting visitors to actively learn rather than passively receive information. Here we propose how narrative can be used within the design of new technologies to support lifelong learning in a cultural setting. Narratives can be used to construct explanations and make sense of the world. Narrative is also central to collaboration and the building of community identity. Heritage collections, whether held privately or curated by a cultural institution convey narratives. Our conceptualisation of narrative, learning theory and curatorial practice indicates that new technology in the cultural domain should: support active interpretation; help reveal the context and process underpinning cultural artefacts; support learning and creativity; and address the challenge to provide an experience that is both entertaining and educational.
\end{abstract}

\section{Introduction}

The aim of our ongoing work is to develop innovative technologies and methodologies that enable the celebration and exploration of regional heritage. This will be realised through the development of sustainable cultural heritage forums that will allow communities of interest to explore and build heritage content. A core technical innovation within the cultural heritage forums will be the development of narrative tools to support the exploration of available content, and also allow visitors to create their own personal and shared stories and collections. Narrative concepts are proposed as an approach because heritage collections and presentations can be understood from a narrative perspective, and narrative theory can motivate the development of presentations and collections that are coherent, engaging and educational.
The rest of this paper will initially introduce the concept of narrative, its use in new technology and its relation to learning theory. Heritage collections and contemporary curatorial trends will then be viewed from a narrative and learning theory perspective. Finally we will outline our approach to using narrative and learning concepts to support the exploration of heritage content.

\section{Narrative}

We define narrative as the particular way in which a story is told. A story is a conceptual space representing events, people and objects. A story may be told in a number of ways, to create different effects, such as humour or surprise. Any of these specific ways in which a story is told are narratives. This follows the definition of story and narrative provided by Brooks [1].

Specific narratives conform to different structural patterns, in order to emphasise different aspects of the story or put over a specific message. Schank [2] identifies a range of patterns that he terms 'story skeletons' that can be used to construct a particular narrative from a story. These patterns describe the conceptual associations made by the narrative and the order in which they are made. Schank claims that these story skeletons are categorised in terms of the gist of the story that they can relate such as 'avenging a wrongdoing', rather than purely in terms of the narrative structure.

A narrative that relates a series of events generally has a plot. As described in Murray [3], E. M. Forster claims that any plot will emphasise causal relationships between events in the narrative. A narrative of an event should therefore present both what happened and an explanation of why it happened.

Narratives, particularly if relating fiction, employ additional structural elements. Commonly a narrative will introduce and then resolve a series of conflicts, the story ending when all conflicts introduced in the story have been resolved. This type of pattern 
maintains the readers' interest in the story, and actively involves them as they try to predict how conflicts will be resolved and evaluate the resolutions provided in the narrative. This is an important aspect, as it demonstrates that narrative applies not only to the structures formed by the teller of the story, but also those constructed by the reader. The reader does not just receive the narrative but actively constructs a story for themselves during the reading process.

\section{Narrative and new technology}

The advent of hypertext led to the expectation of many new narrative forms as the technology allowed us to break out of the confines imposed by paper. However, the ways in which hypertext afforded new narrative forms was not so straightforward. Essentially, new technology provides narrative with greater potential for reader immersion and reader control [4]. Immersion is the feeling of being inside the story. Although the reader of a book often has the feeling of being immersed in the story, new technology offers additional potential as the reader could explore a virtual world, perhaps from the viewpoint of one of the characters in the story. Control is the ability of the reader to influence the course of the story, by making decisions at important junctures in the story, or even taking control of one of the characters. In practice, control offered to the reader of a story generally has to be severely limited, otherwise the coherence of the story cannot be guaranteed, as the reader may wish to lead the digital narrative in a direction not supported by the computational story mechanisms. Additionally, studies of readers [3] have often found them sometimes disaffected by stories over which they have control, as they can have the feeling that a more satisfying story ending may have been available to them if they had controlled the story in a different way. However some successful digital narratives have been designed. One example is the narrative hub, where the reader is initially presented with the ending of the story, such as a dramatic accident, and then has the possibility to explore how and why this occurred by tracing the earlier movements of the characters involved. However in this case the reader has no control over the plot itself and all readers are presented with the same story conclusion. Digital narrative therefore offers the potential for immersion and control, but does not guarantee reader satisfaction and must be carefully deployed.

\section{Narrative and learning}

Narrative is crucial to learning, both in terms of how individuals construct meanings and how they learn collaboratively within communities of interest. This is particularly clear when learning is viewed from a constructivist perspective [5]. A central assumption of constructivist theory is that the learner is active rather than the passive receiver of instruction. Learning occurs through the active construction of meaning through interactions with the world. Learning is viewed as a social activity in which interactions with others are an integral part of the process. Learning is also seen as primarily contextual and integrated with activity, rather than the accumulation of abstracted facts which often characterises traditional school-based learning. Finally, learning requires motivation - the learner must be fulfilling some purpose, or learning in order to achieve some goal.

Narrative theory complements this view of learning in a number of ways. Schank $[2,6]$ argues that stories are crucial to how we mentally represent the world around us. Memory can be thought of as containing two subsystems: a memory for concepts (which can be termed semantic memory) and a memory for stories (which can be termed episodic memory). Semantic memory can be thought of as a conceptual map, abstracted from experiences. Semantic memory would, for example, be used to represent different schools of painting, its style of painting, and the leading artists of each school. A highly effective source of concepts that come to reside in semantic memory are narratives, which we may come across in for example museum visits, conversations and books. A concept or lesson is often more readily accumulated from a narrative in which it is contained than when told in the abstract.

Interesting events and narratives are themselves mentally represented separately as stories. For example an interesting story about the life of Manet would be represented in episodic memory, as well as knowledge gleaned from the story being stored in semantic memory. The memory for stories is therefore the mechanism by which interesting events and narratives can be remembered individually, and stories themselves are a key source of concepts to be accumulated in semantic memory.

The representation and telling of stories is also an important indicator of cognitive development in children. A young child will recall an experience as a set of temporally ordered but otherwise unconnected events along the lines of "We went to the park, then we went to the café". An older child is able to introduce causal relations into stories such as "We 
played in the park, which made us hungry, so we went to the café".

Stories are not only important for storing and interpreting events, but for learning and interacting in social settings. Narratives provide a vehicle for collaboration, and the sharing of stories is a crucial method of learning in communities. The power of storytelling to support learning in communities is now being realised in many settings including as a mechanism of knowledge sharing in organisations [7].

As mentioned earlier, narratives are not only constructed by the teller of the story but also the recipient. Boland and Tenkasi [8] define the processes of perspective making and perspective taking. When presented with a narrative, the reader makes a perspective, that is, constructs a personal meaning from the narrative. Any narrative is always incomplete to the reader and must be elaborated in order to make sense. This process of sense-making not only allows us to understand others, but also by gaining an understanding of someone else, we are able to view ourselves in new ways. This is the process that Boland and Tenkasi describe as perspective taking. This view also has parallels with Langers' [9] theory of mindful learning. The mindful learner should always be aware of alternative perspectives on a problem or experience, and be aware of how the chosen perspective affects understanding. Langer suggests that probabilistic language is a good way to encourage mindfulness. As she states, scientific research produces probabilistic results that have a context (e.g. most of the time, under the stated circumstances, horses are herbivorous). When transferred to the classroom, these assertions are translated into contextfree facts (e.g. horses are herbivorous). However, the initial statement would provide a far more engaging subject matter for learning than the phrase that is actually used. The student would be able to ponder under what circumstances a horse may not be herbivorous. Langer provides a range of empirical support for her claim that learning mindfully, and learning with materials constructed to encourage mindful learning, provide a more engaging learning experience and equip the learner with knowledge and skills that are more transferable to new contexts.

\section{Narrative and heritage collections}

The organisation or construction of collections has its own theoretical roots, covering all forms of collecting from personal collections (such as philatelists) to professional collectors such as museum curators. As described by Pearce [10] an organisation or curation of objects follows rules akin to those followed when constructing natural language. Objects available to the collector constitute the vocabulary, and rules as to how the objects can be selected and arranged in a collection constitutes the grammar.

Any heritage object has an intrinsic relationship to a particular event but has a metaphorical relationship to others. Pearce describes how a jacket from the Battle of Waterloo has an intrinsic relationship to the battle itself, but can be used metaphorically in stories of this or other events. For example, the jacket could be used in a story of the Bakerloo uprising in which members of the British public demonstrating against social conditions were overcome by soldiers wearing similar uniforms to those worn at Waterloo.

Collections have important associations to narrative. First, a collection is itself a narrative, telling a story through the description and association of objects. Second, any collected item can be used to validate a narrative. An object, such as the jacket mentioned above, has what Pearce calls "the power of the real thing", providing a form of proof or evidence for the story that is told. Third, a narrative can be used to provide an explanation or perspective on an object or set of objects within a collection.

Viewing or constructing collections also has important associations to learning, in particular learning through creativity. The process of collecting, used to curate museums, is also adopted by individual artists in order to organise their personal artefacts and inspire their creative processes [11]. Collecting is also recognised as the initial stage in theories of the creative process, a number of which are described in [12]. Facilitating the collecting process is also seen by Shneiderman [13] as a key goal of computer support for creativity.

\section{Contemporary influences on heritage collections}

Shifting views on the nature and purpose of museum narrative reflect current theories of learning and narrative. Museums used to tell an authorised narrative of events according to official taxonomic (i.e. grammatical) rules. They had a duty to instruct the visiting public according to the specified narratives. This view of the museum was challenged by Barthes [14], among others, who stressed that an exhibition should be understood within its socioeconomic context. A narrative of an exhibition should therefore be understood as reflecting the assumptions of the prevailing culture, rather than telling the only true story.

Below we describe five influences of relevance to our current research project. The works mentioned can be found in [11] which also provides references to the original sources. Additional observations regarding the work of Mark Dion are described in [15]. 
1) Support viewing as active interpretation. Intervention art describes an exhibition constructed by an artist that sits alongside the standing exhibition of the museum, providing a response to it, and highlighting the assumptions made within the narrative of the museum. A number of thought provoking examples have been developed by Fred Wilson, including "Mining the Museum" exhibited in Maryland, USA in 1992. Wilson brought out objects from the reserve collection concerned with slavery, and juxtaposed them with already displayed objects, to present an alternative historical perspective seemingly repressed by the museum narrative. Other artists have used unexhibited objects in order to bring to light the curatorial agenda. Eduardo Paolozzi's "The Lost Magic Kingdoms" was organised from unexhibited ethnographic objects of the British Museum. Such exhibits serve to question the museum's selection process by constructing an exhibit from objects that could be thought of as having less value and unworthy of public display. Any museum collection is therefore constructed from a particular perspective and adopts a set of value judgements. Visitors should be aware of, and evaluate, these assumptions and the social context from which they arose. As stated earlier, effective learning should be an active process and narrative (collections) should be interpreted and reconstructed by the reader.

2) Represent objects in context to reveal associations. Conventional museums have been criticised for repressing the context surrounding the objects on display. Mark Dion compares museums to butterfly collections, in which a butterfly is removed from the habitat in which it exists (and in which it can be understood) and displayed alongside other butterflies. In an art context, Dion goes onto suggest that the paintings of Manet would be better understood if exhibited with the paintings he was reacting against, rather than other impressionist paintings from 30 years later. Ideally collections should allow visitors to explore objects in context. Learning is more effective when contextualised.

3) Reveal the domain as a dynamic process. As well as repressing context, conventional museums also repressed the process by which the objects were created. Dion claims that process should be built into an exhibition. This should be done by allowing the work to exist in a number of stages and making the evolution of the work available to the viewer. Dion's "Tate Thames Dig" existed in two different forms. First, the bank of the River Thames near the gallery was searched for archaeological and other interesting artefacts, which were cleaned and classified in tents outside the gallery. These tents were open to the public, allowing them to see the archaeological process in action. Second, selected objects retrieved from the archaeological dig were organised inside the gallery in display cases. Another illustrative example is the work of Joseph Cornell who presented an exhibition of his unfinished works in order to reveal his research process to the visitor. Giving access to the process as well as the product provides a more effective and engaging learning experience.

4) Support collecting as a creative and learning process. As mentioned earlier, the process of collecting is not only done by organisations that display cultural objects but also people who create them. Artists collect and organise objects to facilitate their own creative process. Two reasons why collecting supports creativity is that it has a purpose and that it has to contend with a set of constraints. The purpose might be a particular topic the organiser wishes to explore. Constraints include the availability of objects, how they can be aesthetically arranged, and the size and shape of the space in which the objects are to be organised or displayed. In 1991 Peter Greenaway curated the exhibition " 100 Objects to Represent the World". The purpose of the collection was inspired by the U.S. voyager spaceships sending representative objects into space, describing Earth for the benefit of extraterrestrial life forms. Although he claimed the high interconnectedness of objects made the task easier that it may sound, the purpose and constraints of a collection do provide a challenge for the collector, that may require a highly creative solution. Constraints are required to make creativity possible [16].

5) Meet the challenge to be entertaining and educational. Many educationalists have grappled with the problem of how to make a fun learning experience. Many of the issues raised here, could be seen to provide an educational and perhaps engaging experience, but will it be entertaining? Lessons on how to construct entertaining collections can be gleaned from a collecting tradition that predates the public museum. The curiosity cabinet or Wunderkammer was a personal collection that people organised in their houses, either in a display case or dedicated room. Emphasis was placed on unusual objects, strange items from the natural world, games and optical illusions. The purpose was to fill the space with a myriad of objects that inspired curiosity, and also promoted creativity, which is itself a form of learning. The extent to which these kinds of techniques can be used to align entertainment and learning is an open question, but it is certainly the case that learning requires motivation, of which curiosity or entertainment is a good source.

\section{Suggested approach}


We aim to develop new technologies and methodologies that use narrative to provide active, engaging, learning experiences with heritage content. Our initial thoughts on how to provide this can be grouped around the five influences described above.

Active interpretation can be supported by providing the visitor with alternative digital narratives incorporating some or all of the same viewed objects. This allows the set of objects to be considered from different perspectives. Additionally, textual descriptions should be used that encourage mindful learning, rather than the accumulation of facts.

Representation of context can be supported by underlying computational conceptual models (i.e. ontologies) driving the presentation of resources, that can arrange and select objects according to different kinds of association, showing for example how a work of art was painted as a reaction to other art works.

Representation of process can also be supported by conceptual models that represent temporal and causal associations between objects. These models can support the visitor in traversing a work in different stages of completion and noticing patterns in its evolution.

Collecting as a creative and learning process can be supported by user friendly web-based tools for describing objects and organising them in one of a number of virtual spaces. This will be supported by the Resource Annotation Tool (RAT) [17] that enables visitors to describe and cluster online heritage artefacts. This will also draw on Beardon and Worden's [18] work on the Virtual Curator.

Meeting the challenge to be entertaining and educational can be approached by setting up interesting and ill-defined questions to motivate the exploration process and encourage a mindful approach. Computational techniques inspired by the Wunderkammer can be used to select interesting objects, and arrange them in ways that reveal interesting juxtapositions.

A more detailed account of the approach to be taken, in the context of one of our heritage casestudies can be found in [19].

\section{Conclusions}

Narrative is central to how we construct meanings and learn about the world around us. Narratives are constructed by the teller of a story and also reconstructed by the reader. We propose that new technology in a heritage context can employ narrative and learning principles to support: active interpretation; representation of context; representation of process; learning and creativity; and aligning education and entertainment.

\section{Acknowledgements}

This research was conducted within the EU IST funded CIPHER project, IST-2001-32559.

\section{References}

[1] Brooks, K. M. (1996). Do story agents use rocking chairs? The theory and implementation of one model for computational narrative. ACM Mutlimedia '96, Boston, MA. [2] Schank, R. C. (1990). Tell Me A Story: A New Look at Real and Artificial Memory. New York, Macmillan. [3] Murray, J. H. (1997). Hamlet on the Holodeck: The Future of Narrative in Cyberspace. Cambridge, MA, MIT Press.

[4] Ryan, M. (2001). "Beyond myth and metaphor: The case of narrative in digital media." Game Studies(1).

[5] Hein, G. (1996) 'Constructivist Learning Theory', The museum and the needs of people: proceedings of ICOMCECA Annual Conference, Jerusalem, Israel, 15-22 October 1991, 1992 ICOM-Israel, pp.89-94.

[6] Schank, R. C. (1995). What we learn when we learn by doing, Nortwestern University, Institute for Learning Sciences.

[7] Brown, J. S. and P. Duguid (2000). The Social Life of Information. Boston, MA, Harvard Business School Press. [8] Boland, R. J. and R. V. Tenkasi (1995). "Perspective making and perspective taking in communities of knowing." Organization Science 6(4): 350-372.

[9] Langer, E. (2000). Mindful learning. Current Directions in Psychological Science, 9 (6), 220-223.

[10] Pearce, S. M. (1995). On Collecting: An Investigation into Collecting in the European Tradition. London, Routledge.

[11] Putnam, J. (2001). Art and Artifact. London, Uk, Thames \& Hudson.

[12] Lubart, T. I. (2000). "Models of the creative process: Past, present and future." Creativity Research Journal 13(3\&4): 295-307.

[13] Shneiderman, B. (2000). "Creating creativity: interfaces for supporting innovation.” ACM Transactions on Computer-Human Interaction 7(1): 114-138.

[14] Culler, J. (1983). Barthes. London, Fontana.

[15] Corrin, L. C., M. Kwon and N. Bryson (1997). Mark

Dion. London, Phaidon.

[16] Boden, M. A. (1994). Precis of The creative mind: Myths and Mechanisms. Behavioural and Brain Sciences, 17(3), 519-570.

[17] Wolff, A., Z. Zdrahal and Z. Kouba (2002). Tools for Personalised Annotation and Organisation of Diverse Web Resources. DEXA Workshop on Presenting and Exploring Heritage on the Web.

[18] Beardon, C. and S. Worden (1997). The virtual curator: Multimedia technologies and the roles of museums. Contextual Multimedia: Multimedia and Interpretation. E. Barrett and M. Redmond. Cambridge, MA, MIT Press. [19] Collins, T. and P. Mulholland (2002) A cultural heritage forum celebrating technology innovation at Station $X$. DEXA Workshop on Presenting and Exploring Heritage on the Web. 